\title{
Effect of maternal treatment with altrenogest on age at puberty, hormone concentrations, pituitary response to exogenous GnRH, oestrous cycle characteristics and fertility of fillies
}

\author{
J. Naden, E. L. Squires and T. M. Nett \\ Animal Reproduction Laboratory, Colorado State University, Fort Collins, CO 80523, USA
}

\begin{abstract}
Summary. Puberty was studied using 15 fillies of Quarter Horse phenotype. Fillies were from dams treated daily from Days 20 to 325 of gestation with: (1) $2 \mathrm{ml}$ neobee oil per $50 \mathrm{~kg}$ body weight (controls); or (2) $2 \mathrm{ml}$ altrenogest $(2.2 \mathrm{mg} / \mathrm{ml})$ per $50 \mathrm{~kg}$ body weight. The clitoris was measured at birth and approximately every 12 weeks until 84 weeks of age. Blood samples were collected from 9 fillies ( 5 treated, 4 controls) every 4 days over a 28 -day period at 8 -week invervals from 4 to 68 weeks of age; sampling continued every 4 days after 72 weeks of age until first oestrus. Blood samples were collected daily during oestrus ( $\geq 35 \mathrm{~mm}$ follicle) and on Days $4,6,10$, and 14 after ovulation for the first 2 oestrous cycles. GnRH challenges $(5 \mu \mathrm{g} / \mathrm{kg})$ were administered every 8 weeks from 32 to 96 weeks of age. Puberty was defined as the first oestrus with ovulation. Beginning 1 February 1987, fillies were teased daily and their ovaries were examined by ultrasonography every 3 days (daily during oestrus). Fillies were inseminated with $500 \times 10^{6}$ motile spermatozoa from one stallion. Pregnancy was diagnosed by ultrasonography on Days $11,12,15$ and every 5 days until Day 50 after ovulation. Prenatal altrenogest treatment caused clitoral enlargement $(P<0.05)$ and increased serum concentrations of $\mathrm{LH}$ from 1 to 7 months of age. The amount of $\mathrm{LH}$ released in response to exogenous GnRH was greater $(P<0.05)$ in treated fillies at 32, 64, and 72 weeks of age. Treated fillies had higher serum concentrations of FSH from 1 to 4 months $(P<0.05)$, but FSH was lower $(P<0.05)$ in treated fillies before and during first oestrus. Serum concentrations of $\mathrm{LH}$ and FSH peaked transiently at 10 months and LH was depressed from 64 to 88 weeks and began to rise 14 days before first oestrus. Concentrations of FSH began to decline 14 days before first oestrus. The median age at puberty was 90 weeks. Durations of oestrus, dioestrus, and the oestrous cycle were not different between groups and were similar to those for adult mares. First cycle pregnancy rates and overall rates were 100 and $82 \%$ and 100 and $91.7 \%$ for control and treated fillies, respectively $(P>0.05)$. Maternal treatment with altrenogest did alter gonadotrophin secretion before puberty, but had no effect on functional reproductive performance in fillies.
\end{abstract}

Keywords: puberty; mare; hormonal concentrations; fertility; GnRH; oestrous cycle

\section{Introduction}

Exogenous progestagens have been shown to maintain pregnancy in ovariectomized mares used as embryo transfer recipients (McKinnon et al., 1988). The oral progestagen, altrenogest (Regu-Mate: Hoechst-Roussel Agri-Vet Company, Somerville, NJ, USA), has been found to be a non-stressful method of administering progestagens to pregnant mares without altering endogenous secretion of 
progesterone (Shideler et al., 1982; Jackson et al., 1986). However, the effect of administering altrenogest to pregnant mares on reproductive performance of female offspring has not been studied.

Systematic studies of puberty in the filly which examine hormonal changes, ovarian development, and age at puberty are lacking. Wesson \& Ginther (1981) reported that spring-born fillies experienced their first ovulation at 59 weeks of age and described changes in plasma gonadotrophin concentrations for 68 days before the first ovulation. Plasma gonadotrophins were measured in prepubertal fillies from birth to 8 months of age (Wesson \& Ginther, 1980), but it is unlikely that hormonal changes prerequisite for puberty would have been detected.

Knowledge of the normal progression of events before and after puberty is necessary if further research is to be conducted on puberty in the horse. The objectives of this study were to assess: (1) clitoral size; (2) age-associated changes in LH and FSH; (3) GnRH-induced LH and FSH release from 32 to 96 weeks of age; (4) changes in LH and FSH during transition into the breeding season and during the first 2 oestrous cycles; (5) age at puberty and characterization of first oestrous cycles; (6) pregnancy rate; and (7) effect of maternal treatment with altrenogest on these measures.

\section{Materials and Methods}

General. Fifteen cross-bred, light horse fillies born between 6 July and 4 August 1985 were used. Pregnant mares were assigned to one of 2 groups: (1) controls, $2 \mathrm{ml}$ neobee oil per $50 \mathrm{~kg}$ body weight; (2) $2 \mathrm{ml}$ ( $2 \cdot 2 \mathrm{mg} / \mathrm{ml})$ altrenogest per $50 \mathrm{~kg}$ body weight $(0.088 \mathrm{mg} / \mathrm{kg})$. Treatments were administered daily from Day 20 to 325 of gestation. The dosage of altrenogest administered was twice the amount recommended for suppression of oestrus; 13 fillies were born to treated dams and 4 to control dams. Two treated fillies died before 18 months of age; thus, 11 treated and 4 control fillies completed the study.

Foals were maintained on pasture with their dams and had access to a limited amount of creep feed, until weaned at 16-20 weeks of age. Thereafter, fillies were penned together in an outdoor drylot and received alfalfa hay ad libitum. and a measured daily ration of grain which was formulated to meet $100 \% \mathrm{NRC}$ requirements for weanling and growing horses (Lewis, [982).

Clitoral size. The clitoris was measured on some fillies at birth and subsequent measures were taken on some or all fillies at 4, 16, 28, 40, 48, 60, 72 and 84 weeks of age (Table 1). The height and width (mm) of each clitoris were measured twice by 2 technicians. The average total clitoral surface area $\left(\mathrm{mm}^{2}\right)$ was used for statistical analysis.

Age-associated changes in $\mathbf{L H}$ and $\boldsymbol{F S H}$. Nine fillies (4 control and 5 treated) were selected to monitor hormonal changes in prepubertal and pubertal mares. Age-associated changes in LH and FSH were monitored from 4 to 68 weeks of age by collecting 7 blood samples ( 1 every 4 days) at 8 -week intervals. Thus, 6 'windows' were examined and each window contained 7 blood samples. For each filly, the median serum concentrations of LH and FSH during each sampling window were used for statistical analysis. Beginning at 72 weeks of age, blood samples were collected every 4 days until first oestrus. Samples were collected daily during oestrus ( $\geq 35 \mathrm{~mm}$ follicle) and on Days $4,6,10$ and 14 after ovulation for the first 2 oestrous cycles. All samples were collected in the morning by jugular venepuncture.

GnRH challenges. GnRH challenges were administered every 8 weeks from 32 to 96 weeks of age. An indwelling, jugular catheter was positioned in one jugular vein and sutured into place on the day before blood collection. Blood samples were collected at 20-min intervals from 08:00 to 12:00 h before intravenous $\mathrm{GnRH}$ administration (LH-RH L-7134; Sigma Chemical Co., St Louis, MO, USA; $5 \mu \mathrm{g} / \mathrm{kg}$ body weight in $0.15 \mathrm{M}-\mathrm{NaCl}$ ). Blood samples were taken at $15,30,45,60,90,120,180,240$ and $360 \mathrm{~min}$ after $\mathrm{GnRH}$ administration. Three dependent variables were analysed for each of the $9 \mathrm{GnRH}$ challenges. First, baseline hormonal concentrations were calculated by averaging the 2 preGnRH samples. Second, the maximum LH and FSH response was calculated as the highest concentration of hormone achieved after GnRH minus the baseline concentration. Third, the time to maximum hormonal response was calculated as the number of minutes from $\mathrm{GnRH}$ administration to the highest concentration of gonadotrophin achieved.

Hormone assays. All blood samples were allowed to clot at ambient temperature for $1 \mathrm{~h}$, then stored overnight at $5^{\circ} \mathrm{C}$. Serum was harvested by centrifugation the next day. Serum samples were stored at $-20^{\circ} \mathrm{C}$ until assayed for $\mathrm{LH}$ (Nett et al., 1975) and FSH (Nett et al., 1979). The following samples were assayed: (1) all samples collected from 4 to 68 weeks of age; (2) all samples collected during the 60 days before first oestrus and ovulation; ( 3 ) all samples collected during the first 2 oestrous cycles; and (4) the 2 samples collected before GnRH administration and all samples after GnRH. (All pre-GnRH samples were assayed for LH and FSH for the GnRH challenges administered at 40 and 72 weeks of age. No pulsatile release of LH or FSH was detected, presumably due to infrequent sampling. Therefore only the 2 pre-GnRH samples were assayed for LH and FSH for the remaining challenges.) Inter-assay coefficients of variation for these assays were $8 \cdot 1$ and $10.1 \%$ for LH and FSH, respectively. Lower limit of sensitivity (LLS; 1 
standard deviation below the specific counts in buffer control tubes) was $1.33 \mathrm{ng} \mathrm{LH} / \mathrm{ml}$ and $2.00 \mathrm{ng} \mathrm{FSH} / \mathrm{ml}$. A value equal to the sensitivity of the assay was assumed for any sample in which the concentration of hormone was below the sensitivity of the assay.

Characterization of oestrous cycles. Puberty was defined as the age when the first ovulation accompanied by behavioural oestrus occurred. Beginning 1 February 1987, all fillies were teased daily with a stallion to determine behavioural oestrus and ovaries were examined every 3 days by ultrasonography (McKinnon et al., 1987a) to monitor follicular activity. Once a follicle $\geq 35 \mathrm{~mm}$ in diameter was detected, ovaries were examined every other day, or daily if the follicle was advancing rapidly in size. Ovulations were detected by ultrasonography (McKinnon et al., 1987a) and ovaries were examined every 3 days during dioestrus.

Evaluation of fertility. Artificial insemination began when a mare had ovulated twice and established a normal oestrous cycle (at least 3 days of oestrus followed by 8 days of dioestrus). Mares were inseminated with $500 \times 10^{6}$ progressively motile spermatozoa from one stallion beginning on Day 2 or 3 of oestrus and continuing every other day until the end of oestrus. Mares were inseminated for no more than 3 cycles. Pregnancy diagnosis was made by ultrasonography (McKinnon et at., 1987b) on Days 11, 12 and 15, and every 5 days until Day 50 after ovulation.

Statistical analyses. Treatment differences for pregnancy rate and incidence of early embryonic death were compared by using $\chi^{2}$ tests (Steel \& Torrie, 1980). Differences between treatment groups for all other variables were determined by the Wilcoxon rank-sum test (SAS, 1987). Age-related changes in LH and FSH and pituitary response to exogenous GnRH were characterized by plotting the median values of each variable across time.

\section{Results}

\section{Clitoral size}

Treatment of mares with altrenogest during pregnancy caused clitoral enlargement in female offspring (Table 1). Treated fillies had a larger clitoris $(P<0.05)$ at all ages measured except at 4 , 16 and 60 weeks of age.

Table 1. Median clitoral surface area from birth to 84 weeks of age+

\begin{tabular}{lccccc}
\hline & \multicolumn{2}{c}{ Control } & & \multicolumn{2}{c}{ Treated $\dagger$} \\
\cline { 2 - 3 } \cline { 5 - 6 } $\begin{array}{l}\text { Age } \\
\text { (weeks) }\end{array}$ & No. & $\begin{array}{c}\text { Median } \\
\left(\mathrm{mm}^{2}\right)\end{array}$ & & No. & $\begin{array}{c}\text { Median } \\
\left(\mathrm{mm}^{2}\right)\end{array}$ \\
\hline Birth & 2 & $1 \cdot 1$ & & 5 & $2 \cdot 0^{*}$ \\
4 & 4 & $1 \cdot 7$ & & 6 & $2 \cdot 6$ \\
16 & 4 & $2 \cdot 7$ & & 6 & $4 \cdot 2$ \\
28 & 4 & $4 \cdot 0$ & 13 & $5 \cdot 6^{*}$ \\
40 & 4 & $4 \cdot 3$ & 13 & $5 \cdot 7^{*}$ \\
48 & 4 & $5 \cdot 2$ & 13 & $6 \cdot 9^{*}$ \\
60 & 4 & $4 \cdot 1$ & 12 & $5 \cdot 7$ \\
72 & 4 & $4 \cdot 6$ & 12 & $5 \cdot 7^{*}$ \\
84 & 4 & $4 \cdot 0$ & 11 & $5 \cdot 8^{*}$ \\
\hline
\end{tabular}

*Different from control at $P<0.05$.

$\dagger$ Dams treated daily with $2 \mathrm{ml}$ altrenogest $/ 50 \mathrm{~kg}$ body weight from Days 20 to 325 of gestation.

$\$$ The mean standard deviation of clitoral surface area was 0.63 and 0.92 for control and treated fillies, respectively.

\section{Age-associated changes in $\mathrm{LH}$ and FSH}

Maternal treatment with altrenogest resulted in higher $(P<0.05)$ serum concentrations of $\mathrm{LH}$ in fillies at 1, 4, 7 and 16 months of age (Fig. 1). Serum concentrations of FSH were also higher $(P<0.05)$ in treated fillies at 1 and 4 months of age (Fig. 1). 


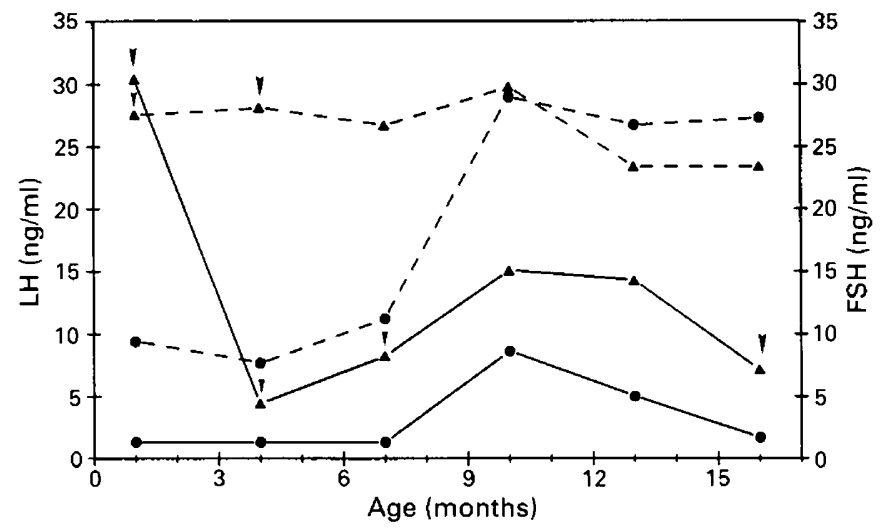

Fig. 1. Age-associated changes in serum concentrations of $\mathrm{LH}(-)$ and $\mathrm{FSH}(---)$ from 1 to 16 months of age (4-week month) in treated $(N=5)(\Delta)$ and control $(N=4)$ (O) fillies. Arrows designate treatment differences $(P<0.05)$. The mean standard deviation for $\mathrm{LH}$ was 2.33 and 10.40 in control and treated fillies, respectively. The mean standard deviation for FSH was $6 \cdot 12$ and $7 \cdot 74$ in control and treated fillies, respectively.

Concentrations of LH (Fig. 1) were not detectable in control fillies from 1 to 7 months, peaked at 10 months and steadily declined to near undetectable levels at 16 months. Treated fillies had high concentrations $(30 \mathrm{ng} / \mathrm{ml})$ of $\mathrm{LH}$ at 1 month which decreased drastically at 4 months (Fig. 1). Thereafter, changes in concentrations of $\mathrm{LH}$ in treated fillies paralleled changes observed in control animals.

Concentrations of FSH (Fig. 1) were low in control animals at 1 and 4 months $(P<0.05)$, rose to a peak at 10 months, and plateaued at 16 months of age. Treated fillies had elevated concentrations of FSH from 1 to 4 months $(27 \mathrm{ng} / \mathrm{ml})$, with changes parallel to control fillies after 10 months of age (Fig. 1).

\section{Changes in LH and FSH during transition into the breeding season}

Serum concentrations of $\mathrm{LH}$ were lower $(P<0.05)$ in control compared to treated fillies on Days $-42,-30$ and -22 before first ovulation (Fig. 2). Serum concentrations of LH fluctuated below $5 \mathrm{ng} / \mathrm{ml}$ in control fillies until Day -14 (Fig. 2). Serum concentrations of LH in treated fillies fluctuated from 5 to $10 \mathrm{ng} / \mathrm{ml}$ and, like controls, began to increase 14 days before first ovulation (Fig. 2).

Serum concentrations of LH continued to increase in both groups until the day of ovulation (Fig. 3). There was no treatment effect $(P>0.05)$ on serum concentrations of LH during the first 2 oestrous cycles (Fig. 3). The pattern of LH secretion was similar during the first and second oestrous cycles, with concentrations increasing a few days before ovulation, reaching maximum values near ovulation, and declining gradually for 4 to 5 days to low, dioestrous concentrations (Fig. 3). However, peak concentrations of $\mathrm{LH}$ were nearly 3 -fold higher during the second oestrous cycle.

Serum concentrations of FSH, unlike LH, were higher $(P<0.05)$ in control fillies on Days $-50,-46,-42,-38,-34,-22$ and -14 before first ovulation (Fig. 2). Concentrations of FSH fluctuated similarly in both treatment groups (Fig. 2). Concentrations of FSH increased from Days -22 to -14 .

Serum concentrations of FSH remained higher $(P<0.05)$ in control fillies on Days $-5,-4$, $-3,-2$ and -1 of the first oestrous cycle (Fig. 3). There was no treatment effect $(P>0.05)$ on concentrations of FSH during the second oestrous cycle (Fig. 3). Concentrations of FSH increased from Day -4 to Day 4, declined gradually to Day 10, then began to rise after Day 10 in both the 

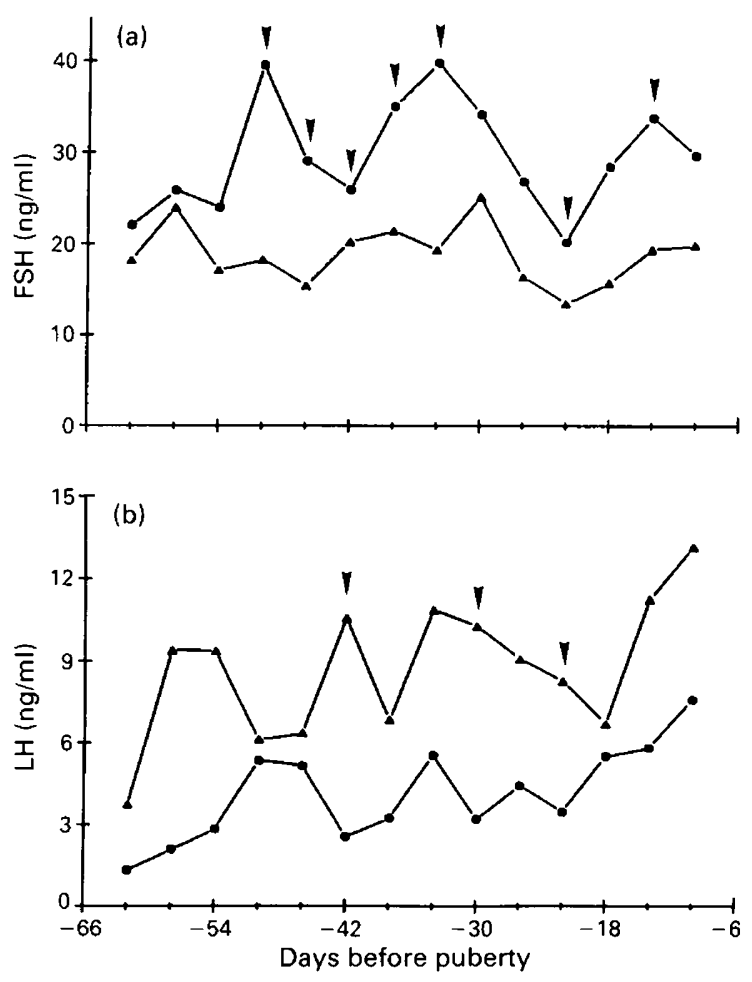

Fig. 2. Serum concentrations of FSH (a) and LH (b) from Day -62 to Day -10 before first ovulation in treated $(N=5)(\Delta)$ and control $(N=4)(\bullet)$ fillies. Arrows designate treatment differences $(P<0.05)$. The mean standard deviation of LH was 2.64 and 5.63 in control and treated fillies, respectively. The mean standard deviation of FSH was 9.77 and 5.47 in control and treated fillies, respectively.

first and second oestrous cycles (Fig. 3). The FSH peak was more clearly defined during the first oestrous cycle than the second cycle (Fig. 3).

\section{LH and FSH response to exogenous GnRH}

Basal concentrations of $\mathrm{LH}$ were higher $(P<0 \cdot 05)$ in treated fillies at 64 and 80 weeks of age (Fig. 4). Concentrations of LH in treated fillies peaked at 40 weeks and gradually declined to 64 weeks; in control fillies values peaked at 56 weeks then declined to 64 weeks (Fig. 4). Basal concentrations of LH were low in control fillies from 64 to 88 weeks then rose dramatically at 96 weeks; treated fillies had a transient rise in serum concentrations of $\mathrm{LH}$ at 80 weeks then increased dramatically after 88 weeks of age (Fig. 4).

Basal concentrations of FSH were lower $(P<0.05)$ in control fillies at 32 weeks of age (Fig. 5), which was consistent with results presented in Fig. 1. Basal concentrations of FSH were erratic from 32 to 96 weeks of age, but seemed to follow similar trends in the treated and control groups (Fig. 5).

The amount of $\mathrm{LH}$ released in response to exogenous $\mathrm{GnRH}$ was greater $(P<0.05)$ in treated fillies at 32, 64 and 72 weeks of age (Fig. 4). Maximum LH response increased in control fillies from 32 to 56 weeks, declined to a nadir at 72 weeks and gradually increased to 96 weeks (Fig. 4). Maximum $\mathrm{LH}$ response was more variable in treated fillies, declining dramatically from 32 to 40 

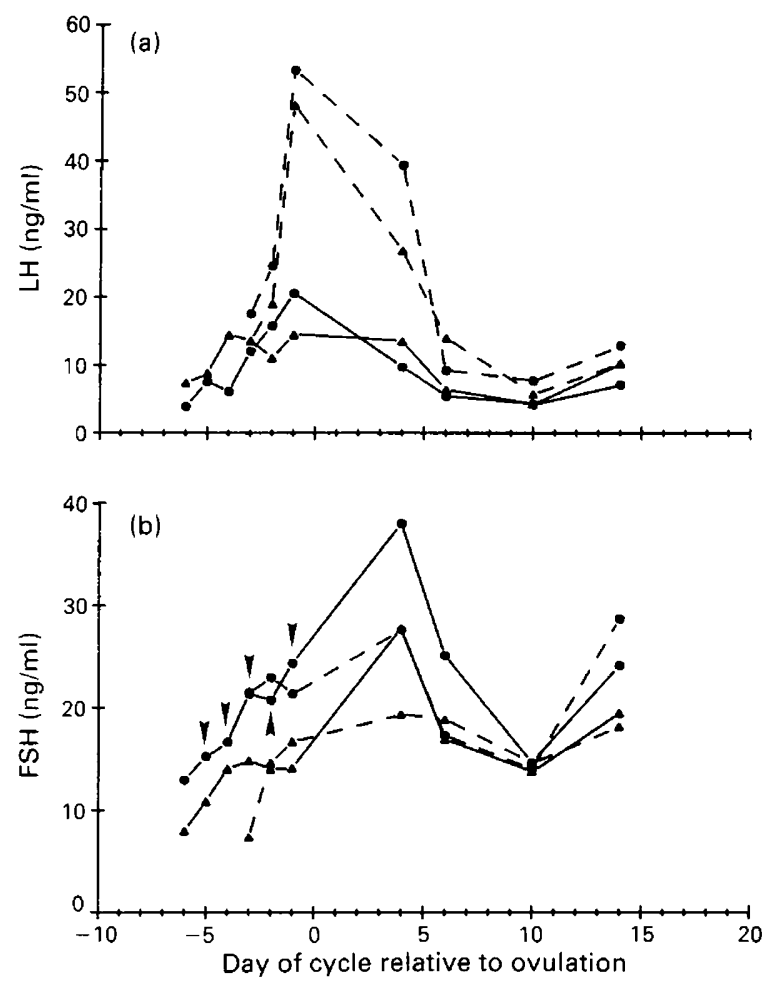

Fig. 3. Serum concentrations of LH (a) and FSH (b) during cycles 1 ( - ) and $2(---)$ for treated $(\mathrm{N}=5)(\Delta)$ and control $(\mathrm{N}=4)(\bullet)$ fillies. Arrows designate treatment differences $(P<0.05)$. The mean standard deviation for $\mathrm{LH}$ was 8.39 and 7.08 for control and treated fillies, respectively. The mean standard deviation for FSH was 5.66 and 8.85 in control and treated fillies, respectively.

weeks, peaking at 48 and 64 weeks, declining to a nadir at 88 weeks and increasing slightly to 96 weeks (Fig. 4).

There was close synchrony between changes in baseline concentrations of LH and changes in GnRH-induced LH release in control fillies (Fig. 4). This relationship was ill-defined in treated animals; basal concentrations of LH dropped before the decline in $\mathrm{LH}$ response after 48 weeks and then the GnRH-induced $\mathrm{LH}$ response began to increase before basal concentrations at 72 weeks of age (Fig. 4).

GnRH-induced FSH release tended to be less in treated fillies, but was different $(P<0.05)$ from controls only at 80 weeks of age (Fig. 5). FSH release increased in control fillies from 32 to 56 weeks, decreased at 64 weeks, peaked again at 72 weeks, then declined steadily to 96 weeks (Fig. 5). However, in treated fillies, GnRH-induced FSH release declined from 32 to 48 weeks of age, peaked transiently at 56 and 72 weeks, then remained low until 96 weeks of age (Fig. 5). The maximal FSH release after exogenous GnRH declined after 80 weeks of age, which was opposite to the change in LH response after 80 weeks. Changes in basal concentrations of FSH were synchronous with changes in GnRH-induced FSH release from 48 to 80 weeks of age (Fig. 5).

Time to maximize concentrations of $\mathrm{LH}$ and FSH response after exogenous GnRH administration was not affected $(P>0 \cdot 05)$ by prenatal, maternal treatment with altrenogest. Time to maximum LH release varied from 15 to $45 \mathrm{~min}$ in treated and control fillies (Figs 4 \& 5). The time to maximum FSH release varied from 15 to $60 \mathrm{~min}$ in control fillies, but was constant at $30 \mathrm{~min}$ in treated fillies from 32 to 80 weeks of age, then increased slightly to 96 weeks of age. 

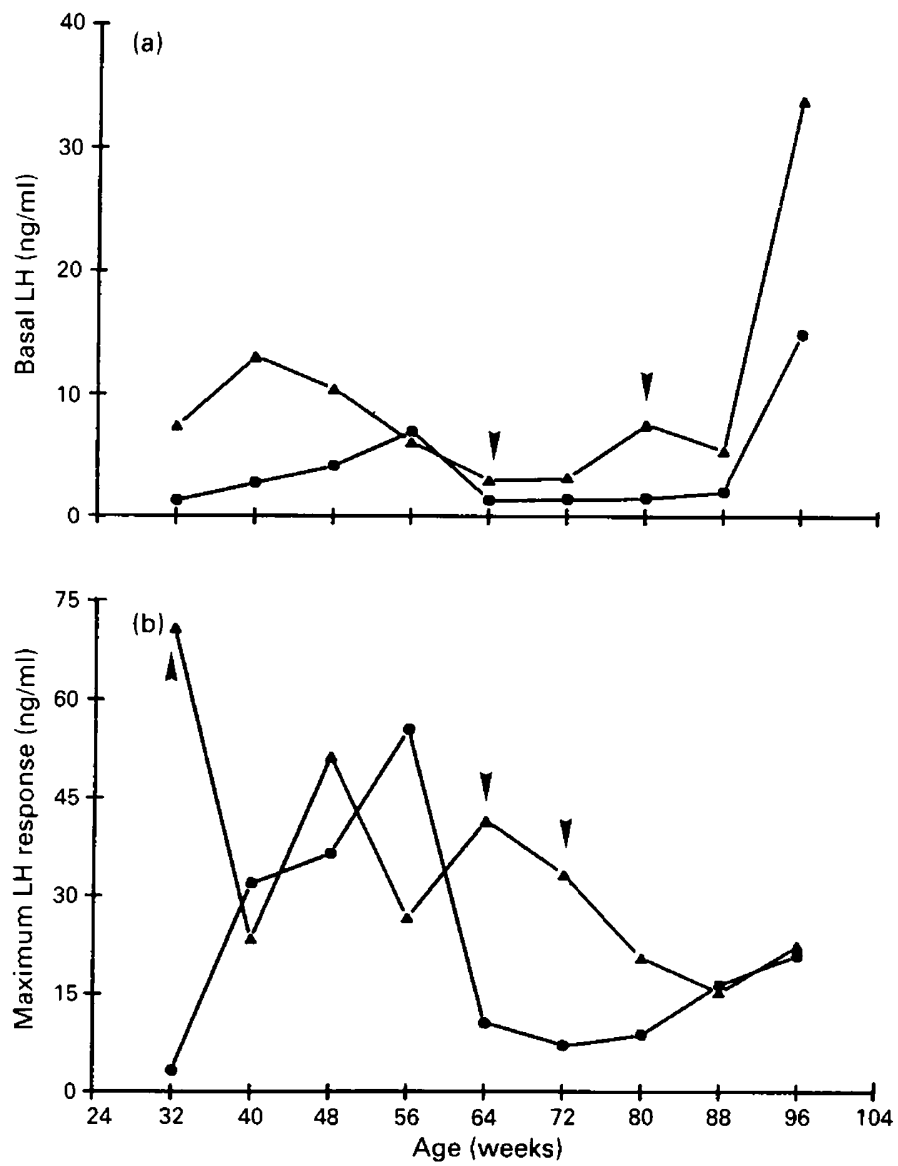

Fig. 4. Basal concentrations of LH (a) and maximum LH response to exogenous GnRH administration (b) from 32 to 96 weeks of age in treated $(N=5)(\Delta)$ and control $(N=4)(\bullet)$ fillies. Arrows designate treatment differences $(P<0.05)$. The median standard deviation of basal concentrations of LH was 5.92 and 14.81 in control and treated fillies, respectively. The mean standard deviation of maximum LH release after GnRH was 20.12 and 30.71 in control and treated fillies, respectively.

\section{Age at puberty}

Puberty was defined as first oestrus with ovulation. Median age at puberty was 90 weeks (range 83-94 weeks) for treated and control fillies $(P>0.05)$.

\section{Characteristics of the oestrous cycle}

The durations of oestrus, dioestrus and the oestrous cycle were not affected $(P>0.05)$ by maternal treatment for the first 2 oestrous cycles. There was no effect $(P>0.05)$ of maternal treatment with altrenogest on the diameter of the largest preovulatory follicle for the first three oestrous cycles. The size of the preovulatory follicle was similar $(40-45 \mathrm{~min})$ for all 3 oestrous cycles.

\section{Fertility}

The first-cycle pregnancy rate was $100 \%$ and $81.8 \%$ for control and treated animals respectively $(P>0.05)$. No statistical comparisons could be made between treatments for the 2 nd and 3 rd cycle 

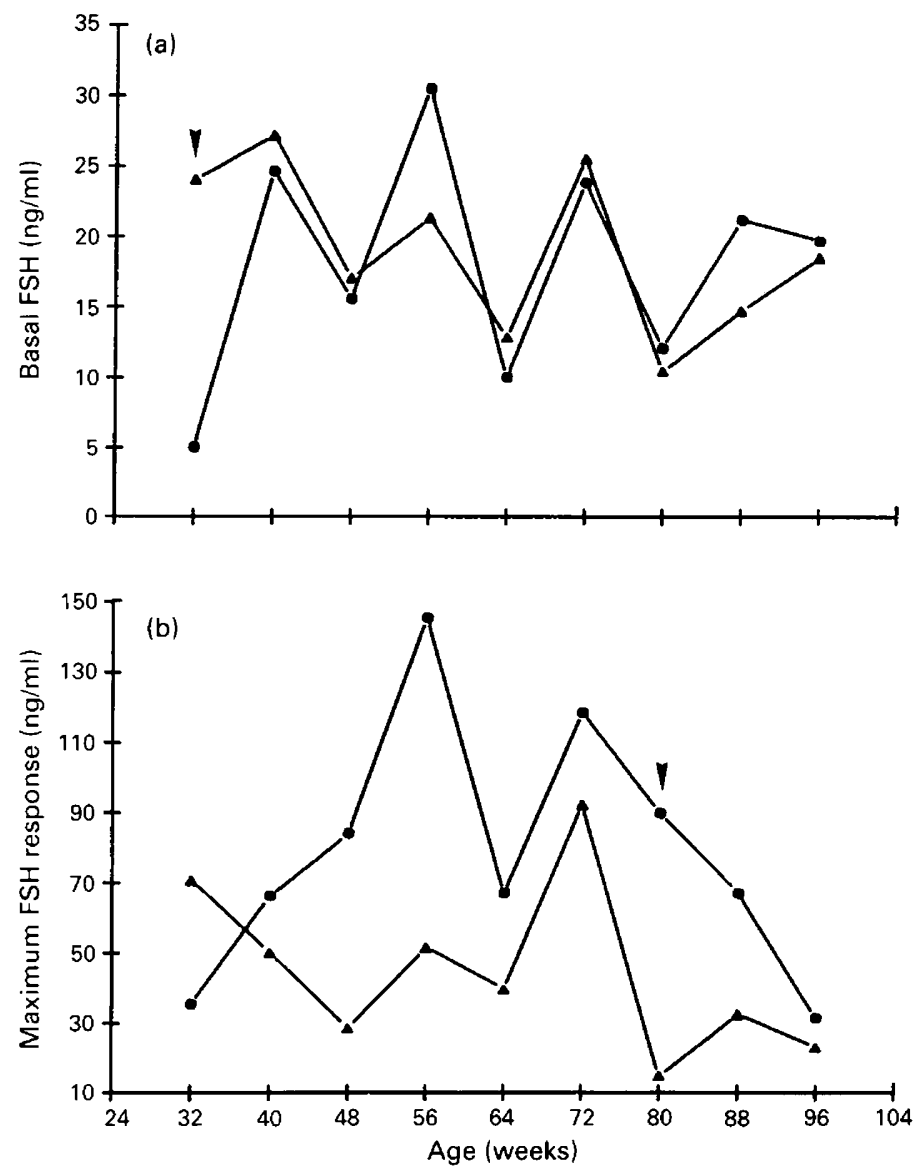

Fig. 5. Basal concentrations of FSH (a) and maximum FSH response to exogenous GnRH (b) from 32 to 96 weeks of age in treated $(N=5)(\Delta)$ and control $(N=4)(\bullet)$ fillies. Arrows designate treatment differences $(P<0.05)$. The mean standard deviation of basal concentrations of FSH was 5.81 and 9.02 in control and treated fillies, respectively. The mean standard deviation of maximum release of FSH after GnRH was 37.29 and 25.99 in control and treated fillies, respectively.

pregnancy rates due to the $100 \%$ pregnancy rate in control fillies at the 1 st cycle. Two treated mares did not become pregnant in the first cycle and one treated mare experienced early embryonic death between Days 25 and 30 of gestation and was inseminated again during the 2 nd cycle. Two of 3 treated mares became pregnant during cycle $2(66.7 \%)$. Over 3 cycles, 11 of $12(91.7 \%)$ treated mares were pregnant at Day 15 and 4 of $4(100 \%)$ control mares were pregnant at Day 15 $(P>0.05)$.

No control mares experienced pregnancy loss before Day 50, while 2 of $12(16.7 \%)$ treated mares experienced early embryonic death $(P>0.05)$. The 50 -day pregnancy rate was $81.8 \%$ and $100 \%$ for treated and control mares, respectively $(P>0.05)$.

\section{Effect of altrenogest on gonadotrophin secretion}

Administration of altrenogest to pregnant mares caused female offspring to have higher serum concentrations of LH early in life (1-7 months; Fig. 1). This trend persisted until the onset of first oestrus (Figs 2 \& 3). Treated fillies had higher serum concentrations of FSH early in life (1-4 
Table 2. Median time to maximum release of $\mathbf{L H}$ and FSH after injection of $5 \mu \mathrm{g} \mathrm{GnRH} / \mathrm{kg}$ body weight

\begin{tabular}{|c|c|c|c|c|}
\hline \multirow[b]{2}{*}{ Weeks } & \multicolumn{2}{|c|}{$\begin{array}{l}\text { Time to maximum LH } \\
(\mathrm{min})\end{array}$} & \multicolumn{2}{|c|}{$\begin{array}{l}\text { Time to maximum FSH } \\
(\min )\end{array}$} \\
\hline & $\begin{array}{l}\text { Control } \\
(\mathrm{N}=4)\end{array}$ & $\begin{array}{l}\text { Treated } \\
(\mathrm{N}=5)\end{array}$ & $\begin{array}{l}\text { Control } \\
(\mathrm{N}=4)\end{array}$ & $\begin{array}{l}\text { Treated } \\
(\mathrm{N}=5)\end{array}$ \\
\hline 32 & $15 \cdot 0$ & $30 \cdot 0$ & $30 \cdot 0$ & $30 \cdot 0$ \\
\hline 40 & 37.5 & $30 \cdot 0$ & 37.5 & $30 \cdot 0$ \\
\hline 48 & $30 \cdot 0$ & $30 \cdot 0$ & $60 \cdot 0$ & $30 \cdot 0$ \\
\hline 56 & $30 \cdot 0$ & $45 \cdot 0$ & $30 \cdot 0$ & $30 \cdot 0$ \\
\hline 64 & $30 \cdot 0$ & $30 \cdot 0$ & $30 \cdot 0$ & $30 \cdot 0$ \\
\hline 72 & 22.5 & $30 \cdot 0$ & $30 \cdot 0$ & $30 \cdot 0$ \\
\hline 80 & $30 \cdot 0$ & $30 \cdot 0$ & $15 \cdot 0$ & $30 \cdot 0$ \\
\hline 88 & $22 \cdot 5$ & $45 \cdot 0$ & 37.5 & 37.5 \\
\hline 96 & $45 \cdot 0$ & $30 \cdot 0$ & $45 \cdot 0$ & $45 \cdot 0$ \\
\hline
\end{tabular}

There was no difference between treatment groups $(P>0.05)$ at any age.

The mean standard deviation for time to maximum $\mathrm{LH}$ release after GnRH was 10.77 and 11.23 in control and treated fillies, respectively. The mean standard deviation for time to maximum FSH release after $\mathrm{GnRH}$ was 15.27 and 12.51 in control and treated fillies, respectively.

months; Fig. 1), but this trend diminished early such that serum concentrations were depressed in treated fillies during the transition to the breeding season (Fig. 2) and first oestrous cycle (Fig. 3). Maternal treatment with altrenogest increased GnRH-induced $\mathrm{LH}$ release at 32, 64 and 72 weeks of age (Fig. 4), but decreased GnRH-induced FSH release at 80 weeks of age (Fig. 5).

\section{Discussion}

The clitoral hypertrophy noted in fillies in the trial was not as dramatic as the enlargement reported for mares treated with anabolic steroids (Maher et al., 1983). Perhaps a lower dose of altrenogest administered for a shorter duration of gestation would result in little or no androgenic effect on female offspring.

Wesson \& Ginther $(1979,1980)$ also reported low concentrations of LH from 1 to 8 or 9 months of age. The higher concentrations of LH and FSH in treated fillies was unexpected since maternal treatment of mares with altrenogest had no effect on gonadotrophin concentrations in colts (Naden et al., 1990a). The pattern of LH secretion in control fillies was similar to that reported for prepubertal ewes Foster et al., 1975) and gilts (Diekman et al., 1983). Changes in concentrations of LH during the first 2 oestrous cycles in the present study were similar to those reported for yearling pony fillies (Wesson \& Ginther, 1981) and adult mares (Whitmore et al., 1983). The lower concentrations of $\mathrm{LH}$ in the first than in the second oestrous cycle were similar to those reported previously for adult mares (Silvia et al., 1986). However, the increase in concentrations of FSH from Day -22 to -14 noted in the present study was different from the gradual decline in concentrations from Day -35 to ovulation reported for adult mares during the spring transition period (Silvia et al., 1986).

The $\mathrm{LH}$ response to $\mathrm{GnRH}$ administration in fillies was similar to the pattern reported for prepubertal colts (Naden et al., 1990b). Season may have affected the LH response since LH release was low or declining after 64 weeks (October) and began to rise after 80 (February) or 88 (March) weeks in control and treated fillies, respectively. Similarly, LH response to exogenous GnRH was 
low during the non-breeding season and increased at first oestrus in adult mares (Silvia et al., 1987). The increased $\mathrm{LH}$ response to $\mathrm{GnRH}$ and the decreased FSH response in both groups of fillies after 80 weeks is similar to that reported for adult mares as the first ovulation of the breeding season is approached (Silvia et al., 1987). Based on data from adult horses the LH response to GnRH was highly correlated to pituitary LH content whereas FSH release after GnRH was not a good indicator of pituitary content (Silvia et al., 1987). It is therefore difficult to discern whether changes in FSH released by GnRH in this study were due to changes in pituitary content of FSH or to changes in pituitary sensitivity to GnRH.

Season and photoperiod appear to affect the timing of onset of puberty in seasonally breeding female animals. Ewes born in the fall did not experience their first ovulation until 49 weeks, whilst spring-born ewes reached puberty at 30 weeks of age (Foster, 1981). Presumably fillies in the present study experienced a delay in age at puberty compared to early-born pony fillies (Wesson \& Ginther, 1981) because they were born late in the year (July and August) and had either not experienced the proper sequence of photoperiod to allow neuroendocrinological maturation or were under the inhibitory influence of short photoperiods when neuroendocrine maturation was achieved (Foster et al., 1985).

Administration of altrenogest to pregnant mares appeared to have a stimulatory effect on the hypothalamic - pituitary axis of female offspring that was diminished by the time of first ovulation. The increased serum concentrations of gonadotrophins in treated fillies after birth could have been due to: (1) a suppression of fetal gonadotrophin secretion which resulted in an increased pituitary content of LH and FSH that was released after the progestagen was removed; (2) an increased pituitary sensitivity/response to GnRH; or (3) a combination of increased storage and increased sensitivity to GnRH. However, these data are not sufficient for determination of the mechanism or site of action of altrenogest on female offspring in utero.

Nevertheless, altrenogest treatment did not affect functional reproductive performance in these fillies. The alteration of serum gonadotrophin concentrations by exposure to altrenogest in utero did not affect age at puberty, oestrous cycle characteristics, pregnancy rates or early embryonic death rates. Presumably, if dams were given the minimum amount of altrenogest required to maintain pregnancy (Shideler et al., 1982), the effect on gonadotrophin secretion in female offspring might be minimized.

The infantile period, which is marked by low gonadotrophin concentrations, appeared to be about 32 weeks after birth in the filly (based on control animals). The beginning of the prepubertal period is marked by changes in the hypothalamic-pituitary axis, which results in increased concentrations of LH and FSH secretion between 32 and 56 weeks of age (Figs 1 \& 4). Serum concentrations of LH were suppressed to a lower level after 56 weeks (Fig $1 \& 4$ ), presumably due to the negative feedback effect of oestradiol on the hypothalamus. Concentrations of LH remained suppressed until 88 weeks of age (Fig. 4). Seasonal effects may have caused LH secretion to remain low for such a long period of time. Concentrations of FSH were erratic from 56 to 88 weeks (Fig. 5), with no obvious seasonal inhibition, and were consistent with reports of no seasonal change in serum concentrations of FSH in adult mares (Turner $e t$ al., 1979).

The transition period into the first ovulatory season was marked by increasing serum concentrations of LH 14 days before first ovulation ( 90 weeks of age; Fig. 2). The patterns of gonadotrophin secretion during the first 2 oestrous cycles (Fig. 3) were similar and were comparable to gonadotrophin secretion in adult, cyclic mares (Evans \& Irvine, 1975). Further studies are needed to determine how factors such as breed, level of nutrition and season of birth affect the temporal relationships between hormonal changes and attainment of puberty.

We thank Dr R. K. Shideler and Dr A. O. McKinnon for attention to the medical needs of the animals in this study; M. E. Crowder-Sousa and T. K. Pope for technical assistance with radioimmunoassays; and V. M. Cook and the numerous graduate and undergraduate students who made completion of this project possible. 
Supported in part by Hoechst-Roussel Agri-Vet Company, Somerville, NJ; Pattridge Family Scholarship Fund, Golden, CO; and CSU Experiment Station.

\section{References}

Diekman, M.A., Trout, W.E. \& Anderson, L.L. (1983) Serum profiles of LH, FSH and prolactin from 10 weeks of age until puberty in gilts. J. Anim. Sci. 56, 139-145.

Evans, M.J. \& Irvine, C.H.G. (1975) Serum concentrations of FSH, LH and progesterone during the estrous cycle and early pregnancy in the mare. $J$. Reprod. Fert., Suppl. 23, 193-200.

Foster, D.L. (1981) Mechanism for delay of first ovulation in lambs born in the wrong season (fall). Biol. Reprod. 25, 85-92.

Foster, D.L., Lemons, J.A., Jaffe, R.B. \& Niswender, G.D. (1975) Sequential patterns of circulating luteinizing hormone and follicle-stimulating hormone in female sheep from early postnatal life through the first year of life. Endocrinology 97, 985-994.

Foster, D.L., Yellon, S.M. \& Olster, D.H. (1985) Internal and external determinants of the timing of puberty in the female. J. Reprod. Fert. 75, 327-344.

Jackson, S.A., Squires, E.L. \& Nett, T.M. (1986) The effect of exogenous progestins on endogenous progesterone secretion in pregnant mares. Theriogenology 25, 275-279.

Lewis, L.D. (1982) Feeding and Care of the Horse, p. 226. Lea and Febiger, Philadelphia.

Maher, J.M., Squires, E.L., Voss, J.L. \& Shideler, R.K. (1983) Effect of anabolic steroids on reproductive function of young mares. J. Am. vet. med. Assoc. 183, 519-524.

McKinnon, A.O., Squires, E.L. \& Voss, J.L. (1987a) Ultrasonic evaluation of the mare's reproductive tract: Part I. Comp. Cont. Ed. Pract. Vet. 9, 336-345.

McKinnon, A.O., Squires, E.L. \& Voss, J.L. (1987b) Ultrasonic evaluation of the mare's reproductive tract: Part II. Comp. Cont. Ed. Pract. Vet. 9, 472-482.

McKinnon, A.O., Squires, E.L., Carnevale, E.M. \& Hermenet, M.J. (1988) Ovariectomized steroidtreated mares as embryo transfer recipients and as a model to study the role of progestins in pregnancy. Theriogenology 29, 1055-1063.

Naden, J., Amann, R.P. \& Squires, E.L. (1990a) Testicular growth, hormone concentrations seminal characteristics and sexual behaviour in stallions. J. Reprod. Fert. 88, 167-176.

Naden, J., Squires, E.L., Nett, T.M. \& Amann, R.P. (1990b) Effect of maternal treatment with altrenogest on pituitary response to exogenous $\mathrm{GnRH}$ in prepubertal stallions. J. Reprod. Fert. 88, 177-183.
Nett, T.M., Holtan, D.W, \& Estergreen, V.L. (1975) Levels of luteinizing hormone, prolactin and oestrogens in the serum of postpartum mares. J. Reprod. Fert., Suppl. 23, 201-206.

Nett, T.M., Pickett, B.W. \& Squires, E.L. (1979) Effects of Equimate (ICI-81008) on levels of LH, FSH and progesterone during the estrous cycle of the mare. $J$. Anim. Sci. 48, 69-75.

SAS (1987) SAS/STAT Guide for Personal Computers. SAS Inst., Inc., Cary, NC.

Shideler, R.K., Squires, E.L., Voss, J.L., Eikenberry, D.J. \& Pickett, B.W. (1982) Progestagen therapy of ovariectomized pregnant mares. J. Reprod. Fert., Suppl. 32, 459-464.

Silvia, P.J., Squires, E.L. \& Nett, T.M. (1986) Changes in the hypothalamic-hypophyseal axis of mares associated with seasonal reproductive recrudescence. Biol. Reprod. 35, 897-905.

Silvia, P.J., Squires, E.L. \& Nett, T.M. (1987) Pituitary responsiveness of mares challenged with $\mathrm{GnRH}$ at various stages of the transition into the breeding season. J. Anim. Sci. 64, 790-796.

Steel, R.G.D. \& Torrie, J.H. (1980) Principles and Procedures of Statistics: A Biometrical Approach. McGraw-Hill Book Co., New York.

Turner, D.D., Garcia, M.C. \& Ginther, O.J. (1979) Follicular and gonadotropic changes throughout the year in pony mares. Am. J. vet. Res. 40, 1694-1700.

Wesson, J.A. \& Ginther, O.J. (1979) Plasma gonadotropin levels in intact and ovariectomized prepubertal ponies. Biol. Reprod. 20, 1099-1104.

Wesson, J.A. \& Ginther, O.J. (1980) Plasma gonadotropin concentrations in intact female and intact and castrated male prepubertal ponies. Biol. Reprod. 22, 541-549.

Wesson, J.A. \& Ginther, O.J. (1981) Puberty in the female pony: reproductive behavior, ovulation and plasma gonadotropin concentrations. Biol. Reprod. 24, 977-986.

Whitmore, H.L., Wentworth, B.C. \& Ginther, O.J. (1973) Circulating concentrations of luteinizing hormone during the estrous cycle of mares as determined by radioimmunoassay. Am. J. vet. Res. 34, 631-636.

Received 30 March 1989 